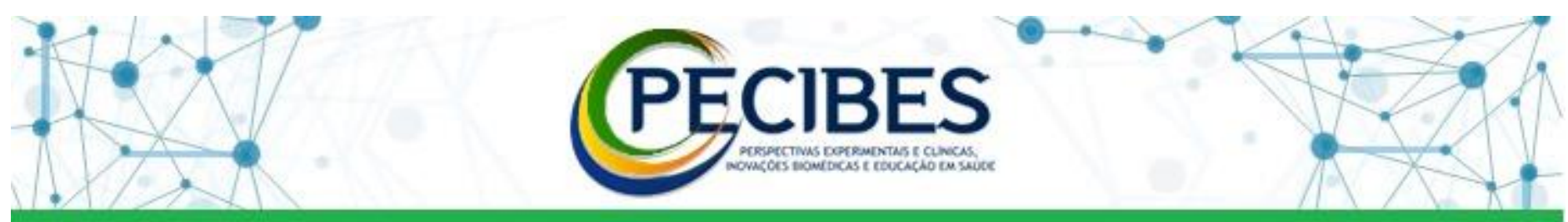

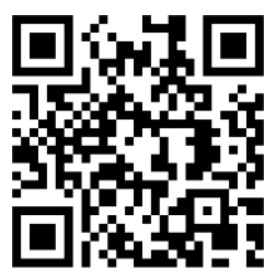

http://www.seer.ufms.b r/index.php/pecibes/ind ex
* Autor correspondente: Ingrid Barbosa Ferreira, Universidade Federal do Mato Grosso do Sul -
UFMS. E-mail do autor: Ingrid.ferreira@uf ms.br

Key-words: Physiotherapy. Urinary Incontinence. Pelvic floor. Assessment. Descriptores: Fisioterapia Incontinência de orina Piso pélvico

Descritores: Fisioterapia. Incontinência Urinária. Assoalho Pélvico. Avaliação.

\section{Avaliação de assoalho pélvico e da composição corporal de mulheres praticantes de cross training}

Pelvic floor muscle assessment and body composition of women cross training practitioners

Ingrid Barbosa Ferreira ${ }^{1}$, Gabriela Gabbi ${ }^{1}$, Lorena Cornacini ${ }^{1}$, Silvio Assis de Oliveira Junior ${ }^{2}$, Ygor Thiago Cerqueira de Paula ${ }^{3}$, Hugo Alexandre de Paula Santana ${ }^{4}$, Ana Beatriz Gomes de Souza Pegorare ${ }^{5}$

1. Aluna de graduação, Curso de Fisioterapia, Instituto Integrado de Saúde (INISA), Universidade Federal de Mato Grosso do Sul (UFMS).

2. Fisioterapeuta, Doutor em Fisiopatologia em Clínica Médica, Docente do Instituto Integrado de Saúde (INISA), Universidade Federal de Mato Grosso do Sul (UFMS)

3. Profissional de Educação Física, Mestrando no Programa de Pós-Graduação em Ciências do Movimento (PPGCMov), Instituto Integrado de Saúde (INISA), Universidade Federal de Mato Grosso do Sul (UFMS)

4. Profissional de Educação Física, Doutor em Sport Physiology and Sport Performance, Docente da Faculdade de Educação (FAED), Universidade Federal de Mato Grosso do Sul (UFMS)

5. Fisioterapeuta, Doutora em Ciências Médicas, Docente do Instituto Integrado de Saúde (INISA), Universidade Federal de Mato Grosso do Sul (UFMS)

Introdução: A prática de exercícios físicos de cross training (CT) tem conquistado muitos adeptos, principalmente mulheres. Apesar dos benefícios desta prática sobre o gasto energético e no condicionamento físico, não se sabe se a prática é benéfica sobre o assoalho pélvico. O exercício físico extenuante pode aumentar a pressão intra-abdominal e é um fator de risco para o desenvolvimento de disfunções do assoalho pélvico. Objetivo: Avaliar assoalho pélvico e a composição corporal (bioimpedância) de mulheres praticantes de CT com e sem sintomas urinários. Métodos: Parecer CEP:4.825.155 aprovado 04 de julho de 2021. Estudo transversal, composto por mulheres adultas praticantes de $\mathrm{CT}$. Os participantes responderam a um questionário que avalia a ocorrência e a gravidade de incontinência urinária e foram submetidas à análise da atividade bioelétrica do assoalho pélvico por meio de equipamento de eletromiografia Miotool da marca Miotec e análise da composição corporal por meio da bioimpedância tetrapolar da InBio. Resultados: Foram avaliadas 1 mulheres com idade média de $37,81 \pm 5,39$ anos e praticantes dos CT por 26,90 $\pm 16,97$ meses participaram deste estudo. Sendo $4(36,3 \%)$ mulheres sem e 7 (63,6\%) com sintomas urinários. Não houve diferença entre as mulheres com e sem sintomas urinários em relação ao tempo de prática de CT, número de gestações e partos, percentual de massa magra e percentual de gordura corporal. Houve diferença significativa entre os seguintes parâmetros da EMG: intensidade média contrações tônicas em uv, tempo antes do pico e tempo após o pico das contrações tônicas. Conclusão: Os resultados reforçam que a presença dos sintomas urinários nestas mulheres está associada a um déficit nas fibras tônicas onde pode ser observado menor atividade bioelétrica, um atraso no início das contrações e menor capacidade de manter a contração tônica ao longo do tempo. 